significant results of OC treatment. The main tasks of OC epidemiology are: continuation of in-depth studies of the prevalence in the regions of the Republic of Kazakhstan with the identification of population groups and regions with the lowest and highest rates of morbidity and mortality from OC. Disclosures Epidemiological data on the incidence rates of malignant neoplasms of the ovaries according to Globocan 2018 show significant differences across countries (per 100,000 women): from 3.8 in Central Africa to 11.9 in Central and Eastern Europe [1].

\section{NEOADJUVANT CHEMOTHERAPY OR FIRST LINE DEBULKING SURGERY IN ADVANCED OVARIAN CANCERS}

${ }^{1}$ Chemseddine Chekman, ${ }^{2}$ Fatiha Gouaref, ${ }^{2}$ Kamel Bentabak, ${ }^{3}$ Fatiha Hadjarrab, ${ }^{3}$ Kamel Bouzid. '2, Rue Mahmoud Zani Scala Elbiar; ${ }^{2}$ Cpme Hospital; Surgery; ${ }^{3} \mathrm{Cpmc}$ Hospital; Medical Oncology

\subsection{6/ijgc-2020-ESG0.222}

Introduction/Background To evaluate the infra-millimetric resectability rate using the two approaches, the morbiditymortality rate and the overall survival curves without recurrence.

Methodology From January 2015 to December 2017, 82 patients with ovarian cancer classified stage IIIC by FIGO (International Federation of Gynecologists and Obstetricians), were treated in the oncological surgery department of the CPMC (Center Pierre et Marie Curie), randomized into two groups. First group (G1) including patients who underwent primary debulking surgery and group 2 (G2), patients who underwent primary chemotherapy with platinum salt followed by cytoreductive surgery (interval surgery).

The anatomo-clinical aspect, the histological type, the intraoperative finding, the procedures performed, the results after surgery, the morbidity and mortality and the survival curves were analysed prospectively.

Results The mean age of patients in G1 was 50.05 years (3080 ) and in G2 55.90 years (23-80), the majority of patients were classified ASA I in both groups $(51,2 \%)$, the mean body mass index (BMI) was 29.16 in the G1 and 27.29 in the G2, the most frequent histological type was serous carcinoma in both groups $(69.5 \%)$ of patients. The main procedure performed is a total hysterectomy, bilateral adnexectomy, infra colic or infra gastric omentectomy, pelvic and lumbar aortic dissection and resection of any macroscopically visible lesion.

In some cases, an associated procedure has been performed such as digestive resection, cholecystectomy, peritonectomy, caudal pancreatectomy. Rate of actions performed in G1: 65.8\%; G2: 34.1\%. Rate of R0 obtained (41.4\%) or $51.5 \%$ in G1 and $48.4 \%$ in G2. The operative morbidity was $20.7 \%$ with a rate of $14.6 \%$ in G1 and $6 \%$ in G2.

Conclusion Complete cytoreductive surgery has become a fundamental principle in surgery for peritoneal carcinomatosis. The gold standard for treating advanced ovarian cancer is complete surgery combined with chemotherapy with platinum salt. The sequence of treatment is still debated, but primary surgery seems to be preferred in terms of recurrence-free survival and overall survival when complete resection (R0) is obtained.

Disclosures Pr Chemseddine CHEKMAN: I declare that I have no conflict of interest.
Dr Fatiha GOUAREF: I declare that I have no conflict of interest.

Pr Kamel BENTABAK: I declare that I have no conflict of interest.

Pr Fatiha HADJARRAB: I declare that I have no conflict of interest.

Pr Kamel BOUZID: I declare that I have no conflict of interest.

\section{6 \\ A RANDOMISED PHASE II STUDY OF NINTEDANIB (BIBF1120) COMPARED TO CHEMOTHERAPY IN PATIENTS WITH RECURRENT CLEAR CELL CARCINOMA OF THE OVARY OR ENDOMETRIUM. (NICCC/ENGOT- OV36)}

${ }^{1}$ Rosalind Glasspool, ${ }^{2}$ lain Mcneish, ${ }^{3}$ Anneke Westermann, ${ }^{4}$ Samantha Hinsley, ${ }^{5}$ Jonathan Ledermann, ${ }^{6}$ ssabelle Ray-Coquard, ${ }^{4}$ Claire Lawless, ${ }^{7}$ Nelleke Ottevanger, ${ }^{8}$ Mansoor Raza Mirza, ${ }^{9}$ Jerome Alexandre. ${ }^{1}$ Beatson West of Scotland Cancer Centre; Institute of Cancer Sciences; ${ }^{2}$ Imperial College London; Irdb Building; ${ }^{3}$ Amsterdam University Medical Center; Department of Medical Oncology F4-224; ${ }^{4}$ Cancer Research UK Glasgow Clinical Trials Unit; Institute of Cancer Sciences, University of Glasgow; Beatson West of Scotland Cancer Centre; ${ }^{5}$ Ud Cancer Institute; Cr-UK and UCl Cancer Trials Centre; ${ }^{6}$ Centre Leon Bérard; Hesper Lab Ea 7425; Université Claude Bernard Lyon Est; ${ }^{7}$ Radboud University Medical Centre; Geert Grooteplein Zuid 8 (Route 452); ${ }^{8}$ Copenhagen University Hospital; Rigshospitalet; Department of Oncology 5073; ${ }^{9}$ Université de Paris; Carpem, Cochin-Port Royal; Oncologie Médicale

\subsection{6/ijgc-2020-ESGO.223}

Introduction/Background Clear cell carcinoma (CCC) is a rare subtype of ovarian and endometrial cancer. It carries a poor prognosis and response to chemotherapy in recurrent disease is low. As angiogenesis pathways are activated in CCC, we performed a trial comparing nintedanib (BIBF1120), an orally available, triple kinase inhibitor targeting VEGFR, PDGFR and FGFR with physician's choice of chemotherapy. As the first randomised trial in relapsed CCC, it gives important information on the efficacy and toxicity of both nintedanib and chemotherapy. Here we report the ovarian cancer (OC) results.

Methodology This was an international, multi-centre, randomised, open label phase II, 3 outcome design. Patients were randomised to nintedanib $200 \mathrm{mg}$ PO twice daily or chemotherapy (paclitaxel $(80 \mathrm{mg} / \mathrm{m} 2$ IV Day 1,8,15), pegylated liposomal doxorubicin $(40 \mathrm{mg} / \mathrm{m} 2 \mathrm{IV})$ or topotecan $(4 \mathrm{mg} / \mathrm{m} 2$ IV Day 1,8,15) every 28 days). Treatment was given until disease progression or unacceptable toxicity. The primary endpoint was progression free survival (PFS) in the ovarian cohort. Secondary objectives included overall survival (OS), response rate (RR), disease control rate (DCR) and patient reported outcomes. With 90 OC patients, the study was powered to detect an improvement in median PFS from 3 to 5 months $(\mathrm{HR}=0.6)$ with $>90 \%$ power, $20 \%$ 1-sided significance. A statistically significant PFS difference at the 1-sided $10 \%$ level (Nintedanib superior) would give a clear signal that a phase III study is warranted. A statistically significant result at the 1-sided 20\% level would require other supportive evidence. EudraCT Ref:2013-002109-73. ISRCTN No: ISRCTN50772895.

Results 91 OC patients were included in the analysis. Median age was 54 years. Median number of previous lines was 2 . After a median follow up of 20.7 months the median PFS was 2.3 months with nintedanib and 1.9 months with chemotherapy (hazard ratio $=0.79,80 \% \mathrm{CI}=(0.58,1.06), \mathrm{p}$ (1-sided) 